Article

\title{
Ferrocene-Based Porous Organic Polymer (FPOP): Synthesis, Characterization and an Electrochemical Study
}

\author{
Željko Petrovski ${ }^{1,2, *(\mathbb{D})}$, Mateus P. Moreira ${ }^{1} \mathbb{D}$, Andreia F. M. Santos ${ }^{2} \mathbb{D}$, Sunny K. S. Freitas ${ }^{1,2}$, Noémi Jordão ${ }^{2} \mathbb{D}$,

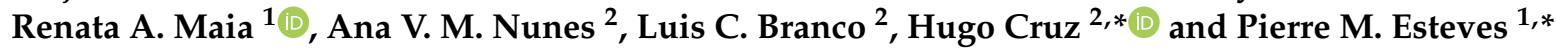

1 Instituto de Química-UFRJ Avenida Athos da Silveira Ramos, $\mathrm{n}^{\circ}$ 149, Bloco A-7º andar Centro de Tecnologia-Cidade Universitária, Ilha do Fundão, Rio de Janeiro 21941-909, Brazil; perissemateus@gmail.com (M.P.M.); sunnykarelly@gmail.com (S.K.S.F.); renataavena@gmail.com (R.A.M.)

2 LAQV-REQUIMTE, Department of Chemistry, NOVA School of Science and Technology, NOVA University of Lisbon, Campus de Caparica, 2829-516 Caparica, Portugal; afm.santos@campus.fct.unl.pt (A.F.M.S.); n.jordao@campus.fct.unl.pt (N.J.); avn07929@fct.unl.pt (A.V.M.N.); l.branco@fct.unl.pt (L.C.B.)

* Correspondence: z.petrovski@fct.unl.pt (Ž.P.); hg.cruz@fct.unl.pt (H.C.); pesteves@iq.ufri.br (P.M.E.)

\section{check for} updates

Citation: Petrovski, Ž.; Moreira, M.P.; Santos, A.F.M.; Freitas, S.K.S.; Jordão, N.; Maia, R.A.; Nunes, A.V.M.; Branco, L.C.; Cruz, H.; Esteves, P.M. Ferrocene-Based Porous Organic Polymer (FPOP): Synthesis,

Characterization and an

Electrochemical Study. Electrochem 2022, 3, 184-197. https://doi.org/ 10.3390/electrochem 3010011

Academic Editor: Masato Sone

Received: 7 February 2022

Accepted: 24 February 2022

Published: 27 February 2022

Publisher's Note: MDPI stays neutral with regard to jurisdictional claims in published maps and institutional affiliations.

Copyright: (C) 2022 by the authors. Licensee MDPI, Basel, Switzerland. This article is an open access article distributed under the terms and conditions of the Creative Commons Attribution (CC BY) license (https:// creativecommons.org/licenses/by/ $4.0 /)$.

\begin{abstract}
Ferrocene-based porous organic polymers (FPOPs) were prepared from phenol-formaldehyde polymer (Bakelite) and phenol as starting materials; and two possible mechanisms for polymerization were discussed. Solid-state ${ }^{13} \mathrm{C}$ CP-MAS NMR, FTIR, powder XRD, elemental analysis and ICP (Fe, Na, B) were performed to characterize the prepared materials. The two synthetic approaches produced polymers with different pore sizes: the FPOP synthesized through Bakelite presented a higher surface area $\left(52 \mathrm{~m}^{2} \mathrm{~g}^{-1}\right)$ when compared to the one obtained by the bottom-up polymerization from phenol (only $5 \mathrm{~m}^{2} \mathrm{~g}^{-1}$ ). Thermogravimetric analysis confirmed the thermal stability of the material, which decomposed at $350{ }^{\circ} \mathrm{C}$. Furthermore, cyclic voltammetry $(\mathrm{CV})$ of the new FPOP on modified electrodes, in ACN and 0.1 M TBAP as an electrolyte, showed fully reversible electron transfer, which is similar to that observed for the ferrocene probe dissolved in the same electrolyte. As a proof-of-concept for an electrochromic device, this novel material was also tested, with a color change detected between yellow/brownish coloration (reduced form) and green/blue coloration (oxidized form). The new hybrid FPOP seems very promising for material science, energy storage and electrochromic applications, as well as for plastic degradation.
\end{abstract}

Keywords: porous organic polymer; ferrocene; Bakelite; cyclic voltammetry; electrochromic material

\section{Introduction}

Phenol formaldehyde resins (PFR) are synthetic materials obtained by condensation of diverse phenol derivatives with aldehydes and were first produced in the nineteenth century. In 1909, Baekeland synthesized the first commercial PFR-based plastic through the reaction of unsubstituted phenol and formaldehyde-Bakelite (see Figure 1a)—which granted PFR the status of the first synthetic resin developed industrially [1]. Nowadays, they are adopted in most plywood and particleboard industries, along with their use in the consumer goods industry. Due to high PFR consumption and the sustainability problems that arise from that, the disposal of these materials has become a relevant issue. Under environmental conditions, plastic degradation occurs by four different mechanisms: (i) photodegradation, (ii) thermooxidative degradation, (iii) hydrolysis and (iv) biodegradation by microorganisms. However, the decomposition process is very slow, turning plastic pollution into a huge environmental problem due to its systematic accumulation and toxic degradation [2]. Currently, the only widely employed method for recycling plastic is the mechanical approach, in which plastic is recovered by washing, followed by shredding, melting and remolding. Nonetheless, this approach cannot be applied to thermosetting materials, such as Bakelite, since their rigid 3D structure, obtained by chemical polymerization, impairs its remodulation. For example, Bakelite can be burned, pyrolyzed or successfully 
employed in the synthesis of a ferrosilicon alloy [3], as well as in the production of silicon carbide [4].

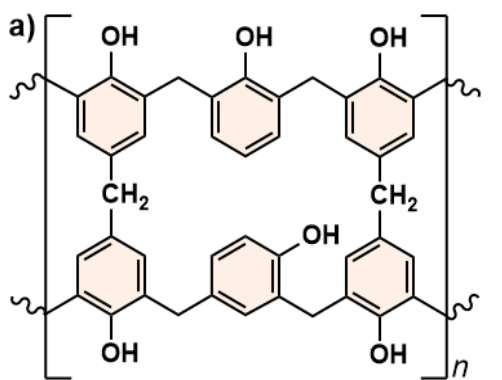

$\mathrm{MW}\left(\mathrm{C}_{44} \mathrm{H}_{36} \mathrm{O}_{6}\right)_{\mathrm{n}}=660.753 \mathrm{~g} \mathrm{~mol}^{-1}$ per $n$ b)

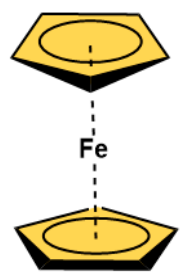

c)

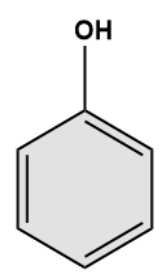

Figure 1. Chemical structures of the starting materials used in the FPOPs syntheses: (a) Bakelite skeleton, $(\mathbf{b})$ ferrocene $(\mathrm{Fc})$ structure and $(\mathbf{c})$ phenol $(\mathrm{Ph})$. For reference, the approximate Bakelite molecular formula is $\left(\mathrm{C}_{44} \mathrm{H}_{36} \mathrm{O}_{6}\right) n$ [5-7].

Among iron based organic molecules, ferrocene is quite stable under ambient conditions and is an interesting organometallic compound due to its high reactivity that provides pathways for easy functionalization, promoting several substituted materials, particularly through a direct Friedel-Crafts reaction [8]. It is known that polymers containing ferrocene in their backbone usually involve the covalent attachment at both cyclopentadienyl rings via divalent $1,1^{\prime}$-ferrocenylene (or ferrocenediyl) units within the main chain [9]. The incorporation of covalently bounded ferrocene (see Figure 1b) into a polymer can be performed in two ways: (i) bottom-up, where the polymerization is from ferrocene and phenol, and (ii) post-synthetic modification, which consists of the addition of ferrocenediyl moieties into the already formed polymer backbone.

Ferrocene-containing polymers are an outstanding class of metal-containing polymer and have recently raised considerable interest, mainly owing to their unique ferrocene properties, such as their higher chemical and thermal stability, the reversible redox behavior of the ferrocene/ferrocenium $\left(\mathrm{Fc} / \mathrm{Fc}^{+}\right)$couple, electrochromic properties, switchable polarity, modified charge transport and electric potential [10]. These characteristics suggest that ferrocene-based polymers are excellent candidates for electrochemical and catalytic applications [11,12], redox-stimuli-responsive drug delivery systems [13], magnetic nanomaterials [14], micellar nanocarriers and smart surfactants [11], self-assembly and surface patterning of nanoparticles [12], as well as for the preparation of porous redox-responsive materials [15].

Porous organic polymers (POPs) are materials that exhibit a highly crossed-linked framework formed by organic building blocks, which are assembled by covalent bonds $[13,16]$. They can be classified as amorphous or crystalline materials. Hyper crossed-linked polymers (HCPs), polymers of intrinsic microporosity (PIMs), covalent organic networks or nanosheets (CONs) and porous aromatic frameworks (PAFs) are examples of amorphous POPs, whereas covalent organic frameworks (COFs) are crystalline. POPs have been employed in several areas, such as gas separation [17], catalysis [18], $\mathrm{CO}_{2}$ capture [19] and biomedicine [20].

Electrochromic materials, also known as switchable materials, are usually found in thin film devices. Moreover, electrochromic smart windows have finally reached maturity and promise to be the next major advance in energy-efficient window technology. These devices are applied in architectural glazing, automotive mirrors, rear view mirrors, sunroofs, sunglasses and in high-end industries. Recent advances have shown the potential of using polymeric and porous scaffolds as very efficient and functional electrochromic materials [21-24], along with different electrochromic ionic liquids and eutectics that have been developed $[25,26]$. 
Herein, we report the development of a Bakelite-like ferrocene functionalized POP and provide a detailed characterization, including a porosity analysis, thermal stability analysis, electrochemical study and propose a potential application in electrochromism.

\section{Results and Discussion}

\subsection{Synthesis and Characterization of FPOP}

In order to incorporate ferrocene in the Bakelite backbone (see Figure 2), two different synthetic approaches were explored:

- Strategy A consisted of the bottom-up method, using phenol, formaldehyde and ferrocene to obtain the desired FPOP;

- Strategy B was based on a post-synthetic modification approach, where ferrocene was incorporated in the already-formed Bakelite (previously prepared by an acid catalyzed reaction from phenol and formaldehyde).

Strategies to obtain ferrocene-based porous organic polymer:

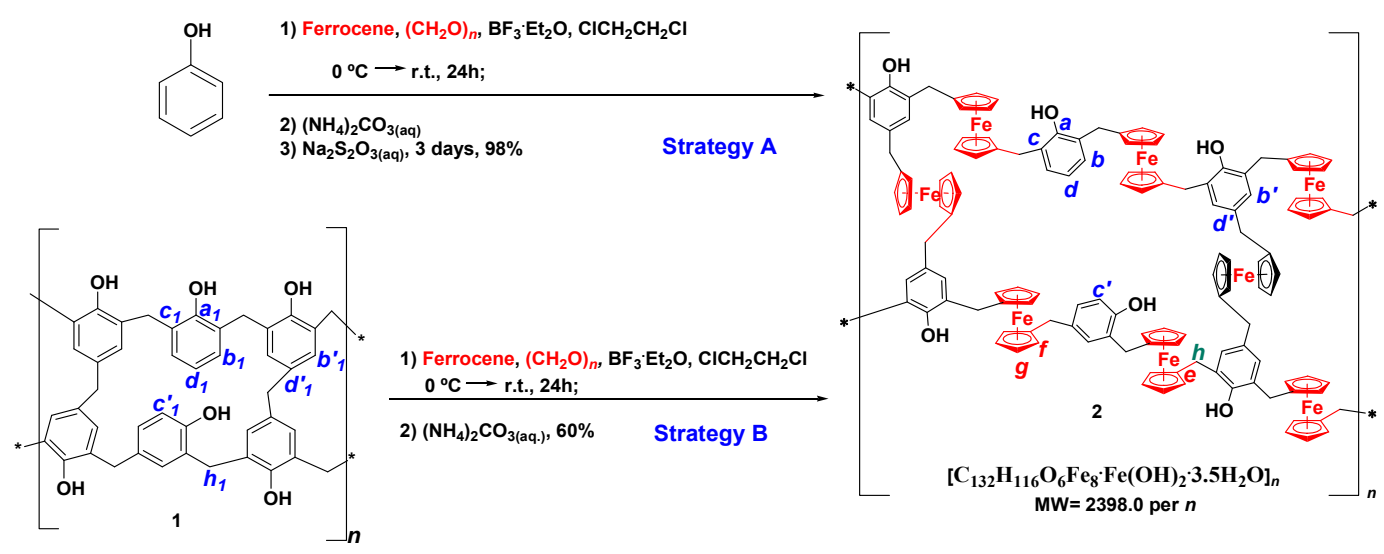

Figure 2. Synthesis of ferrocene-based porous organic polymers (FPOPs), using phenol (Strategy A) and Bakelite (Strategy B) as starting materials. The core Bakelite skeleton is represented in black, in which carbon atoms and groups related to FPOP are highlighted in blue, the inserted $1,1^{\prime}$-ferroenenomethylene unit is in red and the indistinguishable methylene in green.

Regarding bottom-up polymerization (Strategy A), on several attempts, a homogeneous black suspension was consistently formed when quenching the reaction, despite the excess of ferrocene and paraformaldehyde used. Then, the reaction slurry was reduced with thiosulfate solution, over several days, until a stable light brown suspension was formed. The structure of the isolated resulting polymer (see Structure 2 in Figure 2) was determined by ${ }^{13} \mathrm{C}$ CP-MAS NMR and FTIR spectroscopy. In the case of the derivative prepared from Bakelite as starting material (Strategy B), after $24 \mathrm{~h}$, a yellow-brown suspension was formed, along with some black precipitate observed on the walls of the reaction vessel. The reaction mixture was diluted with dichloromethane, quenched with saturated ammonium carbonate solution and the resulting slurry was decanted off from the black precipitate. The structure of the isolated synthesized polymer was evaluated by ${ }^{13} \mathrm{C} \mathrm{CP-MAS} \mathrm{NMR,}$ FTIR spectroscopy, elemental analysis $(\mathrm{C}, \mathrm{H}, \mathrm{N})$ and ICP (Fe, B, Na).

The FPOPs originating from the two different approaches showed similar chemical characterization, although exhibiting some differences in ${ }^{13} \mathrm{C} \mathrm{CP-MAS} \mathrm{(see} \mathrm{Figure} \mathrm{3)} \mathrm{and}$ in the IR fingerprint region (see supporting info). In addition, the black precipitate was revealed to be unstable in air, paramagnetic and, therefore, was not further characterized. 


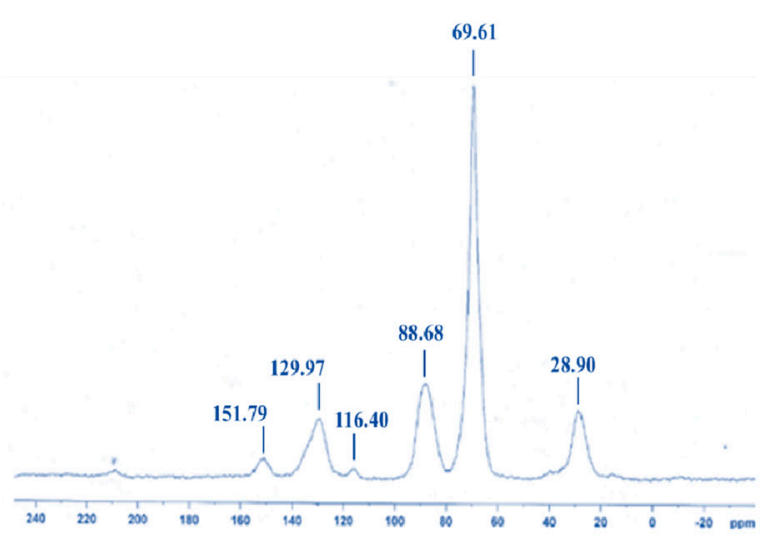

\begin{tabular}{|l|l|l|}
\hline & $\begin{array}{l}\text { strategy A } \\
(\mathrm{ppm})\end{array}$ & $\begin{array}{l}\text { strategy B } \\
(\mathrm{ppm})\end{array}$ \\
\hline a & 155.06 & 151.79 \\
\hline $\begin{array}{l}\text { b, c } \\
\text { d, d' }\end{array}$ & 131.36 & 129.97 \\
\hline c' $^{\prime}$ & 116.55 & 116.40 \\
\hline E & 88.46 & 88.68 \\
\hline f,g & 69.86 & 69.91 \\
\hline H & 29.38 & 28.90 \\
\hline
\end{tabular}

Figure 3. Solid-state ${ }^{13} \mathrm{C} C \mathrm{CP}-\mathrm{MAS}$ NMR spectrum acquired for FPOP prepared by Strategy B. The table includes the comparison of both materials (Strategies A and B).

\section{(a) Characterization by ${ }^{13} \mathrm{C}$ CP-MAS NMR}

In the case of the solid-state ${ }^{13} \mathrm{C}$ CP-MAS NMR spectrum of FPOP, using Strategy $\mathrm{B}$ (Figure 3), it is possible to observe three distinct peaks attributed to the phenol ring at $151.79,129.97$ and $116.40 \mathrm{ppm}$, respectively. These results are in accordance with the ones described for trisubstituted phenol unit of formaldehyde resins [7]. The peak at $151.79 \mathrm{ppm}$ was assigned to carbon a (see Structure 2 in Figure 2). However, the broadness of this signal suggests the presence of mono- and disubstituted phenol groups (156.3-155.8 and 155.1-153.0 ppm, respectively), although the maximum position indicates the prevalence of tri-substitution. Additionally, the broad signal at $129.97 \mathrm{ppm}$ is associated with three different carbons: unsubstituted meta- $\left(b, b^{\prime}\right)$, substituted ortho-(c) and substituted para- $\left(\mathrm{d}^{\prime}\right)$ of the phenolic ring, which can be found at 136-125 ppm. The presence of unsubstituted phenolic para-carbons (d), within the range of 122-120 ppm, cannot be clearly confirmed due to the broadness of the peak at $129.97 \mathrm{ppm}$. Nonetheless, the presence of some unsubstituted ortho-carbons $\left(c^{\prime}\right)$ can be attributed to the minor distinctive peak at $116.40 \mathrm{ppm}$, due to their usual appearance at $117-115 \mathrm{ppm}$ region. The signals at $88.68 \mathrm{ppm}$ and $69.61 \mathrm{ppm}$ represent the carbons of the ferrocene rings $(\mathrm{e}, \mathrm{f}, \mathrm{g})$, pointing to the high ferrocene moiety symmetry incorporated into the polymeric structure like in 1,1'-ferrocenylene.

On the other hand, the solid-state ${ }^{13} \mathrm{C}$ CP-MAS NMR spectrum of FPOP (Strategy B) and ${ }^{13} \mathrm{C}$-NMR of $1,1^{\prime}$-dimethylferrocene solution are similar. In the case of the latter, the chemical shift at $83.66 \mathrm{ppm}$ is assigned to the substituted carbon of the cyclopentadienyl ring, whereas $69.68 \mathrm{ppm}$ and $67.70 \mathrm{ppm}$ are associated with the unsubstituted carbon atoms of the cyclopentadienyl ring. In the case of the spectrum obtained for FPOP (Strategy B), the peak at $88.68 \mathrm{ppm}$ corresponds to the substituted carbon atom of the cyclopentadienyl ring, while the peaks related to two unsubstituted carbon atoms are convoluted and, therefore, cannot be distinguished, producing one broad signal at $69.61 \mathrm{ppm}$. These results are in accordance with the ones reported in the literature, in which the prevalence of $1,1^{\prime}$ dialkylation over 1,3-dialkylation of ferrocene is described for Lewis-acid catalyzed FriedelCrafts alkylation under similar conditions $\left(\mathrm{HfCl}_{4}\right.$ in $\left.\mathrm{CH}_{2} \mathrm{Cl}_{2}\right)$ [27] and for poly(ferrocenylene alkylene)s synthesized by ferrocene addition-condensation polymerization with aldehydes under $\mathrm{BF}_{3} \cdot \mathrm{Et}_{2} \mathrm{O}$ in 1,2-DCE [28]. The dominance of 1,1'-structure over 1,3-dialkylated and other polyalkylated ferrocenes are due to the protic acid catalyzed trans-alkylation (i.e., retro-Friedel-Crafts) reaction, which favors the formation of 1,1'-disubstituted ferrocene. As no acid was added to the reaction media, the most probable protic acid catalyst formed in situ is $\mathrm{BF}_{3} \cdot \mathrm{PhOH}$ (Strategy A) or $\mathrm{BF}_{3} \cdot \mathrm{H}_{2} \mathrm{O}$ (Strategy B) $[29,30]$.

Moreover, the presence of the methylene carbon can be attributed to the unique peak at $28.90 \mathrm{ppm}$ (h). Studies have reported that phenol units of the phenol-formaldehyde resins can be linked by three types of methylene bridges (para-para, ortho-para and ortho-ortho), which can be distinguished in the methylene carbon region of the ${ }^{13} \mathrm{C}-\mathrm{NMR}$ spectra (range 
40.25-40.05, 35.42-35.02 and 30.80-30.30 ppm, respectively) [7]. However, in the case of the prepared FPOP, due to the high distance between the methylene group and the other phenol moiety, only one broad signal associated with the three different methylene bridges is detected in the spectrum.

Finally, the ${ }^{13} \mathrm{C}$ CP-MAS NMR spectra collected from FPOP obtained by Strategies A and $\mathrm{B}$ are similar (see Figure 3 for further details).

\section{(b) Characterization by FTIR}

FTIR spectroscopy is frequently used to determine the compositional structure of phenol-formaldehyde resins [31-34]. The spectrum obtained for the ferrocene-based polymer (Strategy B) showed a broad signal at $3487 \mathrm{~cm}^{-1}$, which can be assigned to water and the phenolic -OH group. The bands at 1611 and $1502 \mathrm{~cm}^{-1}$ are attributed to the C-C aromatic phenol ring moiety, while signals at 1474 and $1430 \mathrm{~cm}^{-1}$ are related to the aliphatic $-\mathrm{CH}_{2}$. The bands at 1258, 1222, 1105 and $952 \mathrm{~cm}^{-1}$ are associated with C-C-O asymmetric stretch and $\mathrm{C}-\mathrm{H}$ in plane deformations. Moreover, the FTIR spectrum does not include any signal related to these specific ferrocene degradation products: ferrocenium, $\mathrm{Fe}_{2} \mathrm{O}_{3}, \mathrm{Fe}_{3} \mathrm{O}_{4}, \mathrm{FeCO}_{3}$ and complex $\mathrm{Fe}(\mathrm{III})$ carbonates [35-37]. On the other hand, a signal emerging at $478 \mathrm{~cm}^{-1}$, due to $\mathrm{Fe}-\mathrm{O}$ vibration, indicates the presence of hydrated iron(II)hydroxide, which is another degradation product of ferrocene [38-40]. In addition to FTIR measurements, elemental analysis, ICP data, as well as Fe and inorganic $\mathrm{Fe}(\mathrm{II}) / \mathrm{Fe}(\mathrm{III})$ titration, suggest that the most possible structure of FPOP (Strategy B) is $\mathrm{C}_{132} \mathrm{H}_{118} \mathrm{O}_{6} \mathrm{Fe}_{8} \cdot \mathrm{Fe}(\mathrm{OH})_{2} \cdot 3.5 \mathrm{H}_{2} \mathrm{O}$ (see Structure 2 in Figure 2).

It is important to comment on the stability of the novel materials. Both polymers (prepared by Strategies A and B) were kept in an inert atmosphere (nitrogen) and, although they seem stable upon repeated FTIR, the air exposition decreases the intensity of the bands, which is a sign of decomposition. This behavior is evident with the disappearance of the signals associated with $\mathrm{CH}_{2}$ at 1474 and $1430 \mathrm{~cm}^{-1}$. One explanation may be the fact that the material decomposes due to multi-wave redox behavior and an oxidative degradation process [41].

\section{(c) Characterization by PXRD}

FPOP prepared by Strategy B was also characterized using powder XRD (see Figure 4a). The diffractogram acquired shows a low crystallinity profile, with a broad peak at $\sim 15^{\circ}$. The absence of specific diffraction peaks of iron(II) hydroxide, $\mathrm{Fe}_{3} \mathrm{O}_{4}, \mathrm{Fe}_{2} \mathrm{O}_{3}$ might be due to their particle size $(<5 \mathrm{~nm})$. Thus, the weak diffraction signals from the structure are mitigated by the presence of species with a higher scattering factor (iron), randomly oriented within the pores, which dominates the scattering [42].

\section{(d) Characterization by BET}

The Brunauer-Emmet-Teller (BET) specific surface area obtained by nitrogen adsorption isotherm at $77 \mathrm{~K}$ of the ferrocene modified Bakelite indicated a type IV isotherm (mesoporous material) and a BET area of $52 \mathrm{~m}^{2} \mathrm{~g}^{-1}$ (Figure $4 \mathrm{~b}$ ). The pore size distribution (see the inset of Figure $4 \mathrm{~b}$ ), calculated by NLDFT model from desorption branch $\mathrm{N}_{2}$ at $77 \mathrm{~K}$ on carbon cylindrical/slit pores, showed two pore sizes: $12 \AA$ and $53 \AA$, matching with the isotherm type. The hysteresis at the desorption branch could also indicates that there is some degree of pore flexibility, which can be due to the low-barrier rotation of the ferrocene moiety. This possible structural flexibility may be one the reasons for the low crystallinity, as noted above. This same behavior is observed in materials that form nanosheets, whose stacking can generate a structural disorder [43]. The product prepared by Strategy A exhibited a much lower BET specific surface area $\left(5 \mathrm{~m}^{2} \mathrm{~g}^{-1}\right)$, suggesting that there was no formation of a porous material (see Figure S1). 

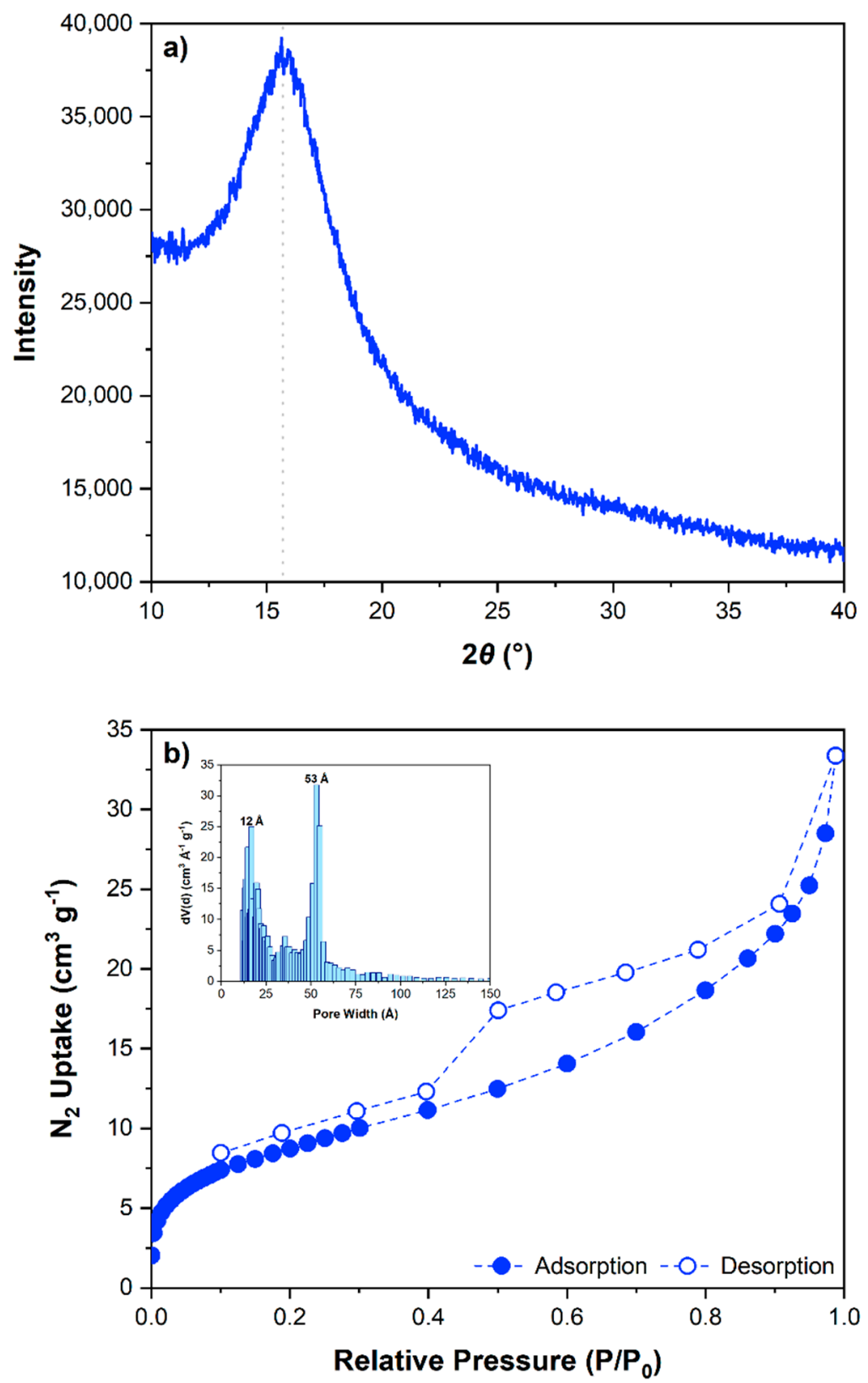

Figure 4. (a) PXRD and (b) $\mathrm{N}_{2}$ adsorption-desorption isotherm and pore size distribution for the FPOP prepared from Bakelite (Strategy B).

\subsection{Differences in Porosity and Proposed Mechanism}

Both pathways A (bottom-up polymerization) and B (insertion of 1,1'-ferrocenenomethylene moieties into Bakelite) produced a similar product in what concerns their chemical characterization, with the unique difference being the need of ferrocenium reduction in Strategy A. As the two polymers also exhibit distinct porosity, the logical postulation is that the mechanism involved in Strategy A is not the same as in Strategy B. The low porosity characteristic of FPOP prepared through Strategy A may be due to the denser packing of the monomers being denser. In the case of Strategy B, the reaction is conditioned by the rigid Bakelite structure and, therefore, the insertion of the 1,1'-ferrocenenomethylene unit into the existing scaffold occurs without mediation of other smaller fragments. In fact, Y. Amamoto et al. [44] has reported an identical effect on pore size enlargement by monomer-controlled insertion of styrene into a polymer.

Regarding the reaction mechanism, both strategies may follow a Friedel-Crafts reaction. However, in the case of Strategy A, polymerization via ortho-quinone methide is 
also possible, as described by S. Gonzales-Pelayo et al. [45]. In contrast, Strategy B can only follow the retro-Friedel-Crafts reaction. Additionally, in Strategy A, it is possible that both ferrocenium and ferrocene fragments are being integrated into the polymer structure, whereas, in Strategy B, only ferrocene is incorporated. The resulting product, FPOP, may undergo further ferrocene oxidation in Strategy A, but not in Strategy B. In the first case, the FPOP, containing ferrocenium as a black slurry, was formed, which required further treatment to obtain a brown polymer, while, in the latter case, a brown FPOP was directly synthesized (see Figure 5). The oxidation process involved in Strategy A was boosted by a strong protic acid $\left(\mathrm{BF}_{3} \cdot \mathrm{PhOH}\right)$ present in the solution from the beginning.
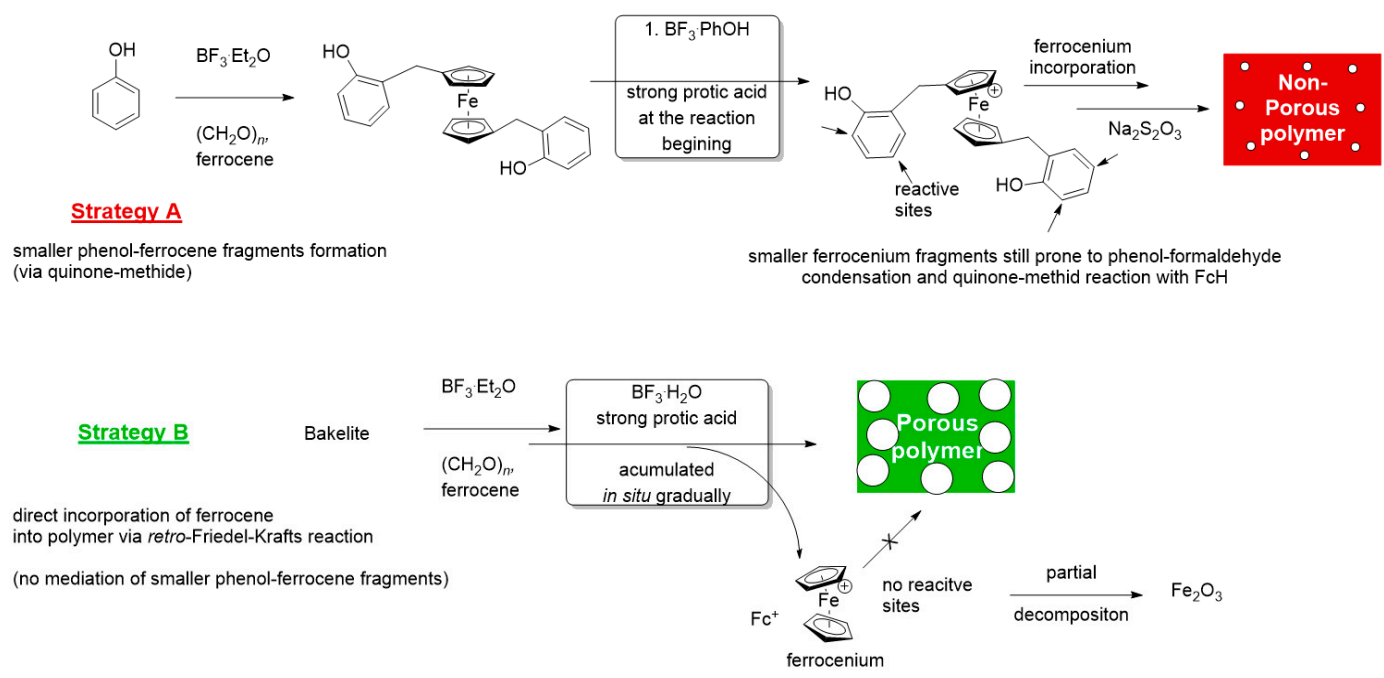

Figure 5. Suggested mechanism for bottom-up polymerization (Strategy A) and insertion into Bakelite (Strategy B).

Moreover, the substituted ferrocenium fragments were incorporated into FPOP by condensation of phenol units (see reactive sites in Figure 5). However, in Strategy B, phenol is confined to the polymer, impairing the ferrocene oxidation process in solution. In this context, the oxidation in the solution could be mediated by increasing the quantity of $\mathrm{BF}_{3} \cdot \mathrm{H}_{2} \mathrm{O}$ that accumulates during reaction.

\subsection{Calorimetric Analyses}

Thermogravimetric analysis (TGA) and differential scanning calorimetry (DSC) were performed to evaluate the thermal behavior of FPOP (Strategy B). In DSC analysis (see Figure S2), after thermal treatment to remove the adsorbed water, no thermal events were detected in the selected experimental conditions for FPOP. On the other hand, TGA (Figure 6) revealed that FPOP started to decompose at approximately $350{ }^{\circ} \mathrm{C}$ with an inflection point, i.e., peak of the first derivative curve of TGA (DTG), at $465^{\circ} \mathrm{C}$.

\subsection{Electrochemical Studies}

\subsubsection{Materials and Methods}

(a) Preparation of the electrolyte for ECD (deep eutectic solvent, DES)

The synthesis of LiOTf:4EG was adapted from the literature [21,26], in which the eutectic system was prepared by vigorous stirring of both components (LiOTf and EG) in a $1: 4$ ratio at a temperature between 60 and $70{ }^{\circ} \mathrm{C}$. After $6-8 \mathrm{~h}$ of mixing, the mixture turned into a colorless viscous liquid. 


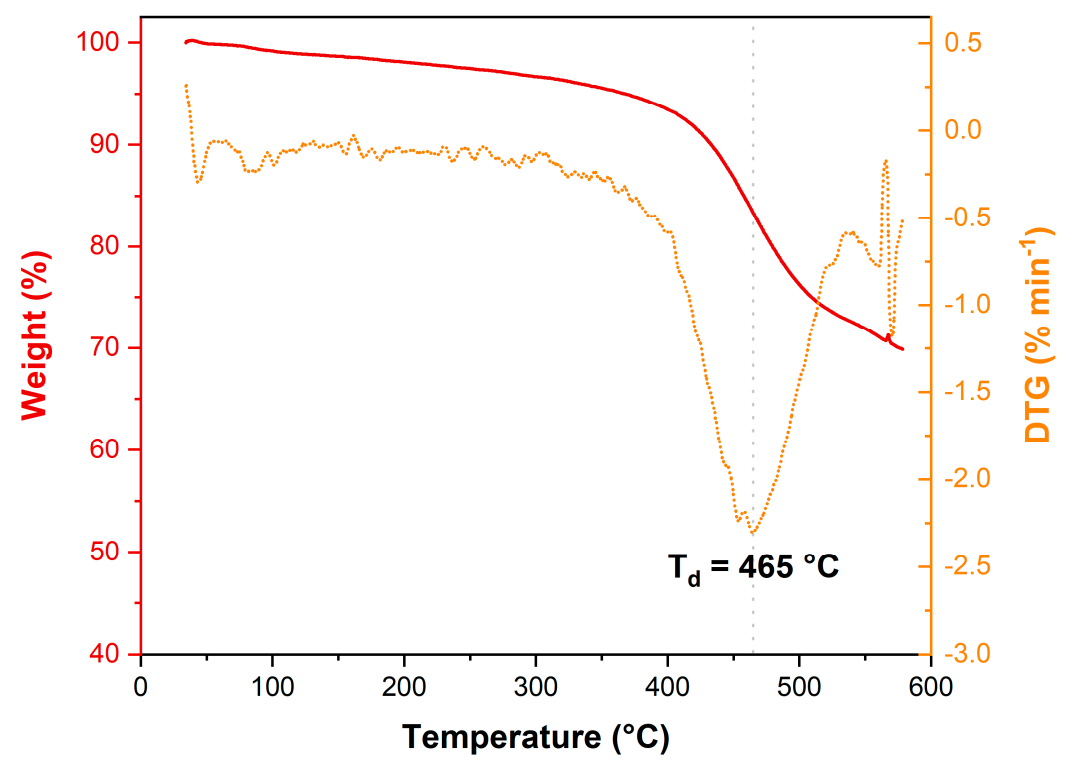

Figure 6. Thermogravimetric curves obtained for FPOP upon heating at a rate of $10{ }^{\circ} \mathrm{C} \mathrm{min}-1$. The decomposition temperature was determined as inflection point, which corresponds to the peak of the first derivative curve of the TGA (DTG).

\section{(b) Cyclic Voltammetry}

Cyclic voltammetry (CV) measurements were performed on an Autolab PGSTAT 12 potentiostat/galvanostat controlled by GPES software version 4.9 (Eco-Chemie B.V., Kanaalweg 29/G, 3526 KM Utrecht, The Netherlands), using a cylindrical three-electrode configuration cell of $5 \mathrm{~mL}$. A glassy carbon electrode (GC) $(\mathrm{d}=3 \mathrm{~mm}$, BASi Corporate Headquarters2701 Kent Avenue West Lafayette, IN 47906, USA) was chosen as the working electrode, while a platinum $(\mathrm{Pt})$ wire acted as an auxiliary (counter) electrode. All potentials refer to SCE (sat. $\mathrm{KCl}$ ) as the reference electrode (Metrohm, Herisau, Switzerland). Prior to use, the working electrode was polished in aqueous suspensions of 1.0 and $0.3 \mathrm{~mm}$ alumina (Beuhler, Leinfelden-Echterdingen, DE) over 2-7/8" micro-cloth (Beuhler, LeinfeldenEchterdingen, DE) polishing pads, and then rinsed with water and ethanol. Different scan rates were carried out to characterize the electrochemical response within the desired electrochemical window (EW).

In order to compare the potential of the commercially available ferrocene with the new porous material (FPOP, Strategy B), the electrochemical behavior of both was studied by cyclic voltammetry (CV) in a three-electrode configuration cell. Acetonitrile and tetrabutylammonium perchlorate $(\mathrm{ACN}+0.1 \mathrm{M}$ of TBAP) worked as the electrolyte. Other experiments performed with $\mathrm{H}_{2} \mathrm{SO}_{4}$ are included in supplementary information. For comparation with FPOP, was used $1 \mathrm{mM}$ of ferrocene, since its electrochemical behavior in several electrolytes is well described [46].

It is important to note that:

- The compound was directly tested in $\mathrm{ACN}+0.1 \mathrm{M}$ of TBAP, as it is the conventional electrolyte, allowing a direct comparison with the redox probes which are used for the study of electrochromic organic material.

- The prepared FPOP, deposited on the electrodes, showed the same behavior as ferrocene. Thus, ferrocene was the electrochromic probe model and it was studied under similar conditions.

- Concerning the electrochromic device (ECD), the deep eutectic solvent LiOTf:4EG was selected as the electrolyte for the two-electrode configuration devices. 


\subsubsection{Electrochemical Studies of Three-Electrode Configuration}

In this work, two types of electrochemical cells were used: three-electrode and twoelectrode configurations. The first one consisted of a standard three-electrode set up to carry out the electrochemical studies and was assembled with a modified working electrode (for the FPOP deposition on a different disk surface, including a glassy carbon disk electrode), $\mathrm{Ag} / \mathrm{AgCl}$ as a reference electrode and $\mathrm{Pt}$ wire as a counter-electrode in a cylindrical cell (see Scheme 1). Before each analysis, the selected electrolyte (ACN + 0.1 M TBAP) was purged with nitrogen for $15 \mathrm{~min}$.

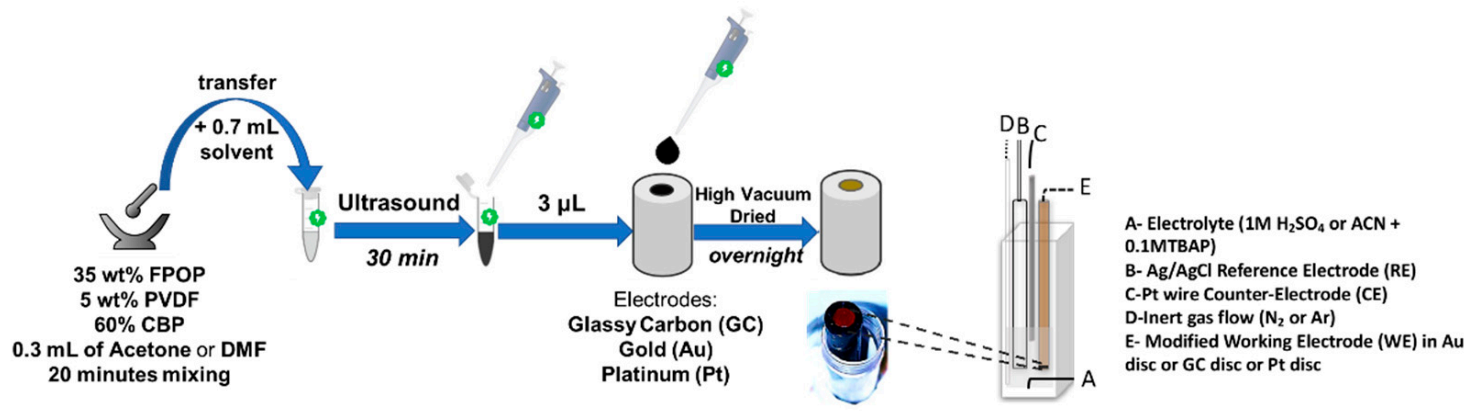

Scheme 1. Modified electrode scheme and the three-electrode configuration cell.

The working electrodes were modified with FPOP or monomer slurries, which were prepared by grinding an adequate amount of active material with a small amount of polyvinylidene fluoride (PVDF) binder and carbon black powder (CBP), all were mixed with a small amount of acetone or DMF for $20 \mathrm{~min}$ in an agate mortar and pestle (see Scheme 1). The paste was subsequently transferred to a vial with an additional amount of solvent and sonicated for $30 \mathrm{~min}$. Finally, a portion of this slurry was pipetted onto the tip of the electrode and then dried under high vacuum conditions overnight before use [47,48].

Cyclic voltammetry studies in the three-electrode configuration cell were performed at several scan rates and in the desired electrochemical window. For a better understanding of the modified FPOP electrochemical behavior, the results were compared against the ones obtained for the ferrocene under the same experimental conditions. Commercial ferrocene has well-known behavior: one reversible electron transfer at standard potential $\mathrm{E}^{0}=390 \mathrm{mV}$ and $\mathrm{E}_{\mathrm{pa}}=430 \mathrm{mV}$ vs. SCE with peak-to-peak separation $\Delta \mathrm{E}=80 \mathrm{mV}$ (see Figure S3 and the first entry of Table 1). Figure 7 illustrates the CV results obtained under the mentioned experimental conditions of the modified electrode on a glassy carbon disk surface GCE/CBP/FPOP at different scan rates $\left(10,20,50\right.$ and $\left.100 \mathrm{mV} \mathrm{s}^{-1}\right)$.

Table 1. Standard potential, anodic peak potential (in $\mathrm{mV}$ vs. SCE) and $\Delta \mathrm{E}_{\mathrm{p}}$ of ferrocene and FPOP modified electrodes in different solvents at $20^{\circ} \mathrm{C}$.

\begin{tabular}{|c|c|c|c|c|c|c|}
\hline Entry & Electrolyte & Material & $\mathrm{E}^{0}(\mathrm{mV})^{(a)}$ & $E_{p a}(m V)^{(b)}$ & $\Delta \mathrm{E}(\mathrm{mV})^{(\mathrm{c})}$ & WE \\
\hline 1 & $\mathrm{ACN}+\mathrm{TBAP}$ & Fc & 390 & 430 & 80 & GC \\
\hline 2 & $\mathrm{ACN}+\mathrm{TBAP}$ & FPOP & 353 & 395 & 85 & GCE/CBP/FPOP \\
\hline
\end{tabular}

The results were calculated using an average value of the scan rates $\left(E_{p}+/-10 \mathrm{mV}\right.$ was accepted as average). Regarding FPOP (second entry of Table 1), there was a potential shift to lower values. The standard potential was $\mathrm{E}^{0}=353 \mathrm{mV}$ and $\mathrm{E}_{\mathrm{pa}}=395 \mathrm{mV}$ vs. SCE and the peak-to-peak separation was $\Delta \mathrm{E}=85 \mathrm{mV}$. A potential shift to lower values suggests an easier oxidation process for the adsorbed material compared to the ferrocene in solution $\left(\mathrm{E}_{\mathrm{pa}}=35 \mathrm{mV}\right.$ and $\left.\mathrm{E}^{0}=37 \mathrm{mV}\right)$. This might be explained by the incorporation of alkyl groups acting as electron donors in the ferrocene ring at position $1,1^{\prime}$, which decreases the 
redox potential when compared to unsubstituted ferrocene (as already described for the simple alkylferrocenes) [49]. Another explanation for this difference could be attributed to the presence of the FPOP directly adsorbed on the electrode surface, promoting the redox process. On the other hand, the diffusion coefficient of the electrolyte could also impact the redox process, as the electrolyte can enter the FPOP pores. Other contributions should be taken into account, such as the electrolyte resistance that could be attributed to the ion diffusion in the electrolyte $\left(\mathrm{ACN}+0.1 \mathrm{M} \mathrm{TBAP}\right.$, containing $\left[\mathrm{N}_{4,4,4,4}\right]^{+}$and $\mathrm{ClO}_{4}{ }^{-}$ions; the difference is related to the geometry of the FPOP modified electrode).

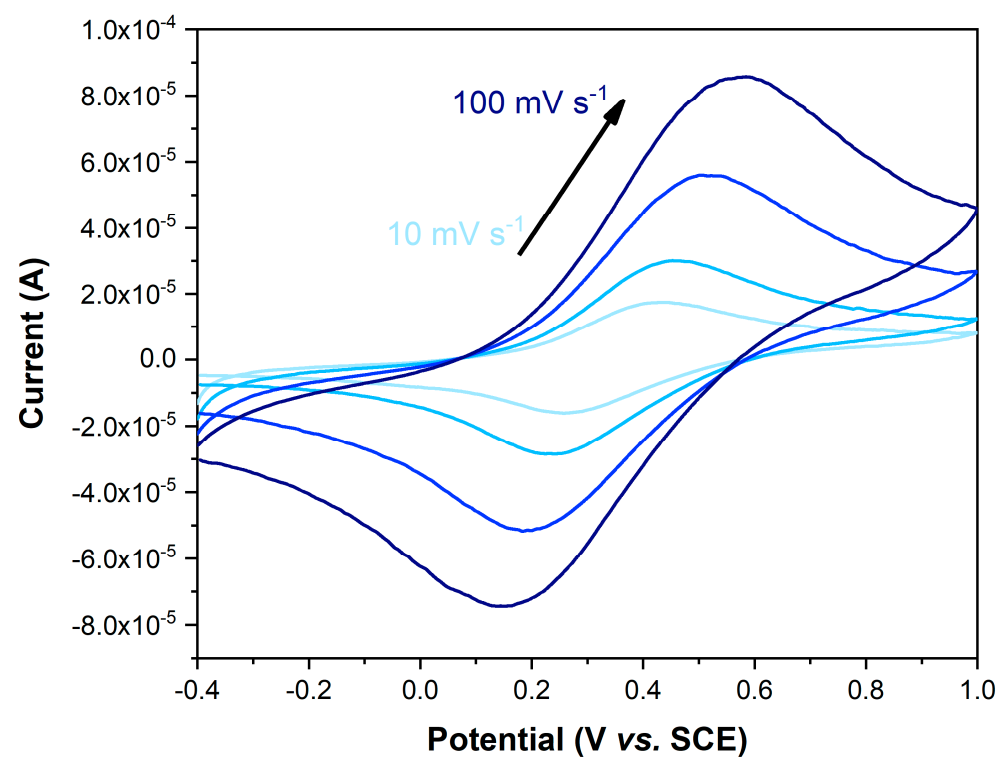

Figure 7. Cyclic voltammogram in $\mathrm{ACN}+0.1 \mathrm{M}$ TBAP of the GCE/CBP/FPOP at different scan rates of $10,20,50$, and $100 \mathrm{mV} \mathrm{s}^{-1}$.

\subsubsection{Electrochemical Studies of Two-Electrode Configuration}

Aiming to evaluate the electrochromic behavior of the ferrocene in the redox activated FPOP, a proof-of-concept of an electrochromic device was assembled using a two-electrode configuration cell (see Scheme 2).

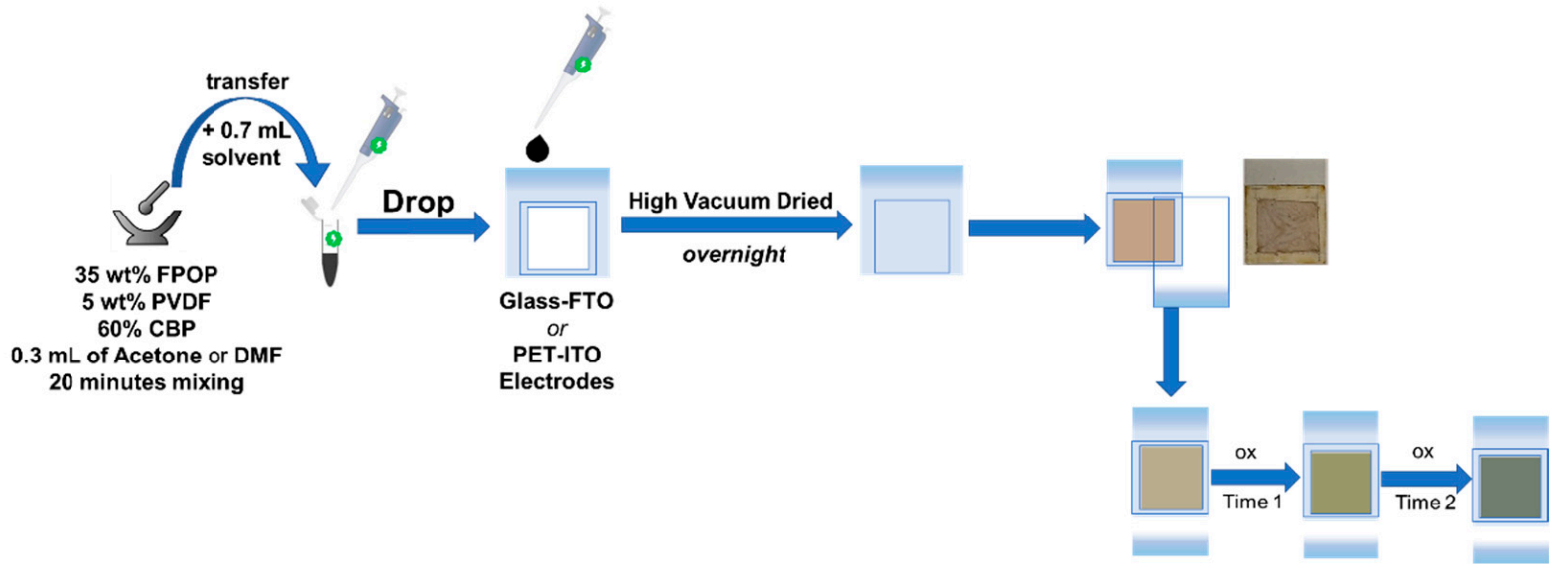

Scheme 2. Schematic of the modified electrodes and ECD assembly.

The cyclic voltammetry study was performed in an EW $(0 / 3 /-3 / 0)$, meaning that the method followed for the measurement was: starting point at $0 \mathrm{~V}$, going at the anodic scan until $3 \mathrm{~V}$, then, reducing upon $-3 \mathrm{~V}$ and finishing at $0 \mathrm{~V}$. Between $3 \mathrm{~V}$ and $-3 \mathrm{~V}$, the sample went to $0 \mathrm{~V}$. The scan rate was $20 \mathrm{mV} \mathrm{s}^{-1}$. First, the cyclic voltammetry of the pure DES 
was performed under same experimental conditions, using glass FTO/LiOTf:4EG/glass FTO to access the electrochemical window of the electrolyte, in order to evaluate if the DES could interfere with the redox process of the FPOP material. The approach was similar to previous studies, in which methyl viologen dichloride was used as the redox probe [26].

The voltammogram acquired for the material exhibits the typical profile for this kind of ECD, as shown in Figure 8. In the first cycle, an electron transfer (ET) occurs at $\sim 1 \mathrm{~V}$ and a second ET can be detected at $\sim 2$ V. However, no color change was observed. As potential was continuously decreased in the cathodic back scan from $3 \mathrm{~V}$ to $-3 \mathrm{~V}$, both ET increase in current intensity (see Figure 8a, light blue dashed line) and the ECD turns into a very light greenish color. In the anodic back scan from -3 to $0 \mathrm{~V}$, no electron transfer was detected.

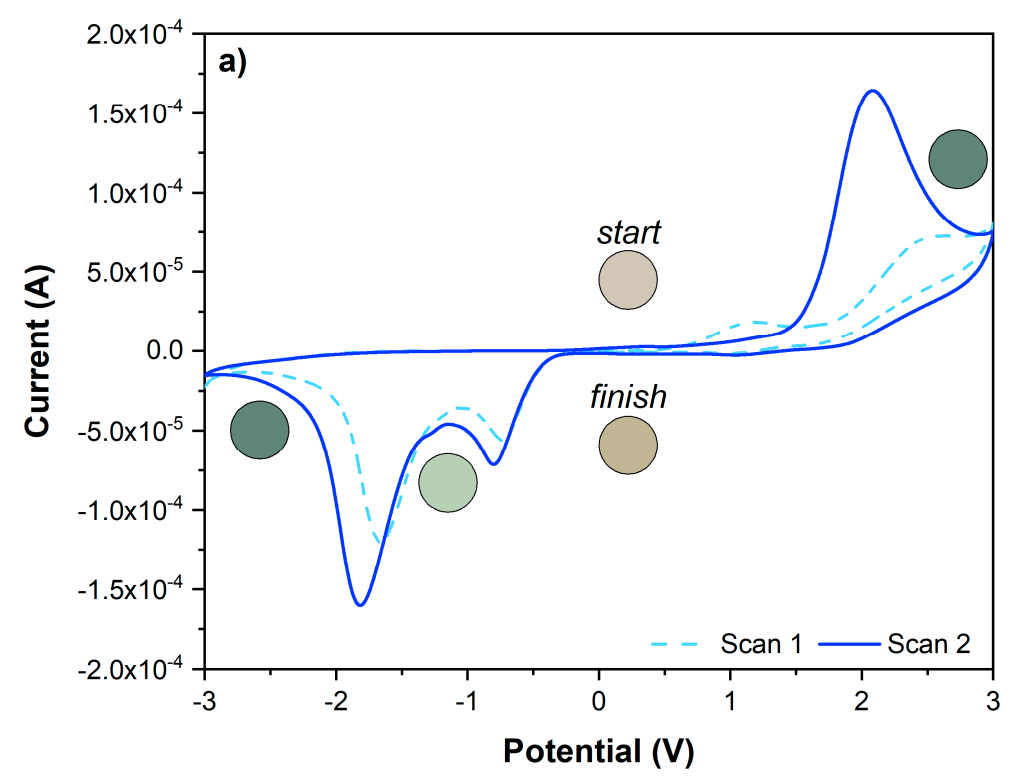

b)

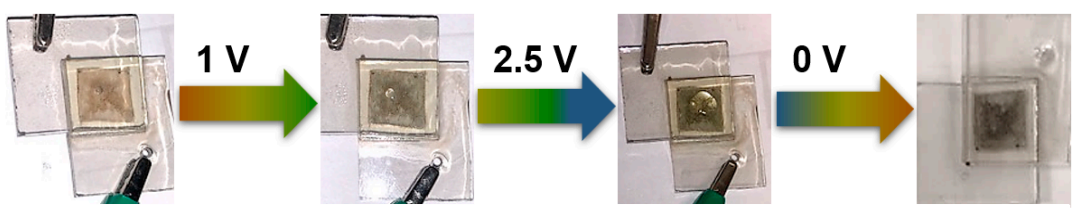

Figure 8. (a) Cyclic voltammograms of the two-electrode device with glass FTO/CBP/PVDF/FPOP electrode in a new electrolyte LiOTf:4EG at $20 \mathrm{mV} \mathrm{s}^{-1}$ (first cycle: light blue dashed line; second cycle: blue solid line) and (b) a proof-of-concept of the ECD color change at different potentials.

Furthermore, in the second cycle (blue solid line), it is observed that both current intensity and coloration increased with the potential, mainly in the peaks located at -2 and $2 \mathrm{~V}$, once the ECD was symmetrical. Afterwards, electrolysis was performed to elucidate the electrochromic behavior for the ECD at different potentials (see Figure 8b). The first one was $1 \mathrm{~V}$ and provided a very light green coloration after $1 \mathrm{~h}$. Then, the applied potential of $2.5 \mathrm{~V}$ for $1 \mathrm{~h}$ resulted in a darker green color. Finally, the recovery of the original coloration was achieved by the application of $0 \mathrm{~V}$ and the ECD partially lost the coloration to a darker brown.

The electrochemical reactions should be balanced when the FPOP is oxidized at the anode (on one side of the ECD). On the other side, we suggest that the counter-balance redox process occurs with some compound at the cathode, probably due to the ethylene glycol (EG) or lithium triflate (LiOTf) which can be reduced. It is also possible that the increased viscosity of DES LiOTf:4EG influences the wettability of the FPOP [50], and consequently the possibility that $\mathrm{Li}^{+}$and $\mathrm{TfO}^{-}$ions or EG occupy the pores of the material. 
The coloration becomes slightly more intense with each cycle. This could be due to a slower electron transfer, as the viscosity of the liquid electrolyte impairs diffusion. Further studies are required in order to clarify all these assumptions.

\section{Conclusions}

In this work, we presented a new porous ferrocene-based organic polymer (FPOP), prepared by two different approaches, which might be source of inspiration to design a new series of porous materials based on this building block. The polymer synthesized from Bakelite (Strategy B) exhibits higher porosity and, therefore, was selected for further characterization. The material presented interesting electrochemical features, including being thermoresistant until $350{ }^{\circ} \mathrm{C}$, properties that are relevant in several applications related to energy and material science. In addition, the proof-of-concept of the ECD shows a reversible color change of FPOP. When the active redox part of the polymer (ferrocene) is reduced, it exhibits brown coloration and, when it is oxidized, it shows greenish coloration. The redox-active FPOP material could be explored for use in energy storage, such as electrode supercapacitors, fuel cells and other electrochemical devices. In this context, it is important to perform further studies to evaluate its viability for applications in the industrial field and for commercial power consumption devices.

Finally, the fact that the resulting polymer is unstable in air seems to be advantageous in the context of plastic decomposition, providing a safeguard mechanism for its degradation.

Supplementary Materials: The following are available online at https:/ /www.mdpi.com/article/10 .3390/electrochem3010011/s1: general information related to the synthesis of the Ferrocene-based Porous Organic Polymer and the characterization techniques. A thermogram of the prepared FPOP is also included, as well as electrochemical studies in $\mathrm{H}_{2} \mathrm{SO}_{4}$ acid media in a three-electrode configuration, and electrolysis to switch coloration of the ECD (plot current vs. time).

Author Contributions: Conceptualization, Ž.P. and P.M.E.; methodology, Ž.P., M.P.M., S.K.S.F. and H.C.; validation, Ž.P., A.F.M.S., S.K.S.F. and H.C.; formal analysis, Ž.P., A.F.M.S., R.A.M. and H.C.; investigation, Ž.P., M.P.M., S.K.S.F., N.J., A.V.M.N. and H.C.; writing-original draft preparation, Ž.P., N.J., R.A.M. and H.C.; writing-review and editing, Ž.P., A.F.M.S., S.K.S.F., L.C.B., H.C. and P.M.E.; supervision, L.C.B. and P.M.E.; project administration, L.C.B. and P.M.E.; funding acquisition, L.C.B. and P.M.E. All authors have read and agreed to the published version of the manuscript.

Funding: This study was funded in part by the Coordenação de Aperfeiçoamento de Pessoal de Nível Superior-Brasil (CAPES)—Finance Code 001 and FCT-CAPES project (2019-2020). The authors also thank the funding agencies FAPERJ, CNPq and Fundação para a Ciência e Tecnologia (PTDC/QUI-QOR/32406/2017, PEst-C/LA0006/2013, RECI/BBBBQB/0230/2012 as well as "SunStorage-Harvesting and storage of solar energy", with reference POCI-01-0145-FEDER-016387. The NMR spectrometers are part of the National NMR Network (PTNMR) and are partially supported by Infrastructure Project $N^{\circ} 022161$ (co-financed by FEDER through COMPETE 2020, POCI and PORL and FCT through PIDDAC). Ž.P. and H.C. acknowledge Fundação para a Ciência e a Tecnologia, MCTES, for the Norma Transitória DL57/2016 Program contract. A.F.M.S. also thanks FCT-MCTES for the PhD Grant (SFRH/BD/132551/2017).

Institutional Review Board Statement: Not applicable.

Informed Consent Statement: Not applicable.

Data Availability Statement: Data available in a publicly accessible repository.

Conflicts of Interest: The authors declare no conflict of interest.

\section{References}

1. Hesse, W. Ullmann's Encyclopedia of Industrial Chemistry; Wiley: Hoboken, NJ, USA, 2000. [CrossRef]

2. Rhodes, C.J. Plastic Pollution and Potential Solutions. Sci. Prog. 2018, 101, 207-260. [CrossRef]

3. Farzana, R.; Rajarao, R.; Sahajwalla, V. Reaction Mechanism of Ferrosilicon Synthesis Using Waste Plastic as a Reductant. ISIJ Int. 2017, 57, 1780-1787. [CrossRef] 
4. Farzana, R.; Sahajwalla, V. Novel Recycling to Transform Automotive Waste Glass and Plastics into SiC-Bearing Resource by Silica Reduction. J. Sustain. Metall. 2015, 1, 65-74. [CrossRef]

5. Farzana, R.; Rajarao, R.; Sahajwalla, V. Transforming Waste Plastic into Reductants for Synthesis of Ferrosilicon Alloy. Ind. Eng. Chem. Res. 2014, 53, 19870-19877. [CrossRef]

6. Maji, S.; Urakawa, O.; Inoue, T. The Structure and Viscoelasticity of Novolac Resins. Polym. J. 2014, 46, 584-591. [CrossRef]

7. Pethrick, R.A.; Thomson, B. 13C Nuclear Magnetic Resonance Studies of Phenol-Formaldehyde Resins and Related Model Compounds 2-Analysis of Sequence Structure in Resins. Br. Polym. J. 1986, 18, 380-386. [CrossRef]

8. Astruc, D. Why Is Ferrocene so Exceptional? Eur. J. Inorg. Chem. 2017, 2017, 6-29. [CrossRef]

9. Enjamuri, N.; Sarkar, S.; Reddy, B.M.; Mondal, J. Design and Catalytic Application of Functional Porous Organic Polymers: Opportunities and Challenges. Chem. Rec. 2019, 19, 1782-1792. [CrossRef] [PubMed]

10. Pietschnig, R. Polymers with Pendant Ferrocenes. Chem. Soc. Rev. 2016, 45, 5216-5231. [CrossRef]

11. Mattoussi, M.; Matoussi, F.; Raouafi, N. Non-Enzymatic Amperometric Sensor for Hydrogen Peroxide Detection Based on a Ferrocene-Containing Cross-Linked Redox-Active Polymer. Sens. Actuators B Chem. 2018, 274, 412-418. [CrossRef]

12. Ghimire, G.; Coceancigh, H.; Yi, Y.; Ito, T. Electrochemical Characterization and Catalytic Application of Gold-Supported Ferrocene-Containing Diblock Copolymer Thin Films in Ethanol Solution. ACS Appl. Mater. Interfaces 2017, 9, $2906-2913$. [CrossRef]

13. Gu, H.; Mu, S.; Qiu, G.; Liu, X.; Zhang, L.; Yuan, Y.; Astruc, D. Redox-Stimuli-Responsive Drug Delivery Systems with Supramolecular Ferrocenyl-Containing Polymers for Controlled Release. Coord. Chem. Rev. 2018, 364, 51-85. [CrossRef]

14. Zhang, X.; Chen, L.; Yun, J.; Kong, J. Novel Ferrocene-Containing Organosilicon Polymers and Uniform Microspheres Prepared by Free Radical Copolymerization: Precursors for Magnetic Si-C-Fe-(O) Nanomaterials. Mater. Des. 2018, 144, 86-97. [CrossRef]

15. Rüttiger, C.; Hübner, H.; Schöttner, S.; Winter, T.; Cherkashinin, G.; Kuttich, B.; Stühn, B.; Gallei, M. Metallopolymer-Based Block Copolymers for the Preparation of Porous and Redox-Responsive Materials. ACS Appl. Mater. Interfaces 2018, 10, 4018-4030. [CrossRef] [PubMed]

16. Kaur, P.; Hupp, J.T.; Nguyen, S.T. Porous Organic Polymers in Catalysis: Opportunities and Challenges. ACS Catalysis 2011, 7, 819-835. [CrossRef]

17. Zhang, T.; Xing, G.; Chen, W.; Chen, L. Porous organic polymers: A promising platform for efficient photocatalysis. Mater. Chem. Front. 2019, 4, 332-353. [CrossRef]

18. Zhang, Y.; Riduan, S.N. Functional Porous Organic Polymers for Heterogeneous Catalysis. Chem. Soc. Rev. 2012, 41, 2083-2094. [CrossRef] [PubMed]

19. Mondal, S.; Kundu, S.K.; Bhaumik, A. A Facile Approach for the Synthesis of Hydroxyl-Rich Microporous Organic Networks for Efficient $\mathrm{CO}_{2}$ Capture and $\mathrm{H}_{2}$ Storage. Chem. Commun. 2017, 53, 2752-2755. [CrossRef] [PubMed]

20. Gomes, R.; Bhanja, P.; Bhaumik, A. A Triazine-Based Covalent Organic Polymer for Efficient $\mathrm{CO}_{2}$ Adsorption. Chem. Commun. 2015, 51, 10050-10053. [CrossRef] [PubMed]

21. Li, Z.; Yang, Y.-W. Creation and Bioapplications of Porous Organic Polymer Materials. J. Mater. Chem. B 2017, 5, 9278-9290. [CrossRef]

22. Rai, V.; Singh, R.S.; Blackwood, D.J.; Zhili, D. A Review on Recent Advances in Electrochromic Devices: A Material Approach Adv. Eng. Mater. 2020, 22, 2000082. [CrossRef]

23. Jarosz, T.; Gebka, K.; Stolarczyk, A.; Domagala, W. Transparent to Black Electrochromism-The "Holy Grail" of Organic Optoelectronics. Polymers 2019, 11, 273. [CrossRef] [PubMed]

24. Shchegolkov, A.V.; Jang, S.-H.; Shchegolkov, A.V.; Rodionov, Y.V.; Sukhova, A.O.; Lipkin, M.S. A Brief Overview of Electrochromic Materials and Related Devices: A Nanostructured Materials Perspective. Nanomaterials 2021, 11, 2376. [CrossRef]

25. Yu, F.; Liu, W.; Ke, S.-W.; Kurmoo, M.; Zuo, J.-L.; Zhang, Q. Electrochromic two-dimensional covalent organic framework with a reversible dark-to-transparent switch. Nat. Commun. 2020, 11, 5534. [CrossRef] [PubMed]

26. Cruz, H.; Jordão, N.; Branco, L.C. Deep Eutectic Solvents (DES) as low-cost and electrolytes for electrochromic devices. Green Chem. 2017, 19, 1653-1658. [CrossRef]

27. Cruz, H.; Jordão, N.; Amorim, P.; Dionísio, M.; Branco, L.C. Deep Eutectic Solvents as suitable electrolytes for Electrochromic Devices. ACS Sustain. Chem. Eng. 2018, 6, 2240-2249. [CrossRef]

28. Ahn, S.; Song, Y.-S.; Yoo, B.R.; Jung, I.N. Lewis Acid-Catalyzed Friedel-Crafts Alkylation of Ferrocene with Allylchlorosilanes. Organometallics 2000, 19, 2777-2780. [CrossRef]

29. Suzaki, Y.; Yoshigoe, Y.; Osakada, K. Cyclic and linear poly(ferrocenylene alkylene)s synthesized from addition-condensation polymerization of ferrocene with aldehydes. J. Polym. Sci. Part A: Polym. Chem. 2013, 51, 3627-3635. [CrossRef]

30. Yoneda, N.; Aomura, K.; Ohtsuka, H. Studies on $\mathrm{BF}_{3}-$ Complex Catalysts in the Alkylation Reaction of Benzene Homologues. Bull. Japan Pet. Inst. 1967, 9, 26-31. [CrossRef]

31. Thakur, R.; Barman, S.; Gupta, R.K. Synthesis of cumene by transalkylation over modified beta zeolite: A kinetic study. Braz. J. Chem. Eng. 2016, 33, 957-967. [CrossRef]

32. Poljanšek, I.; Krajnc, M. Characterization of Phenol-Formaldehyde Prepolymer Resins by In Line FT-IR Spectroscopy. Acta Chim. Slov. 2005, 52, 238-244.

33. Ma, C.-C.M.; Wu, H.-D.; Su, Y.-F.; Lee, M.-S.; Wu, Y.-D. Pultruded Fiber Reinforced Novolac Type Phenolic CompositeProcessability, Mechanical Properties and Flame Resistance. Compos. Part A Appl. Sci. Manuf. 1997, 28, 895-900. [CrossRef] 
34. Huang, J.; Xu, M.; Ge, Q.; Lin, M.; Lin, Q.; Chen, Y.; Chu, J.; Dai, L.; Zou, Y. Controlled Synthesis of High-Ortho-Substitution Phenol-Formaldehyde Resins. J. Appl. Polym. Sci. 2005, 97, 652-658. [CrossRef]

35. Křístková, M.; Filip, P.; Weiss, Z.; Peter, R. Influence of Metals on the Phenol-Formaldehyde Resin Degradation in Friction Composites. Polym. Degrad. Stab. 2004, 84, 49-60. [CrossRef]

36. Vahur, S.; Teearu, A.; Peets, P.; Joosu, L.; Leito, I. ATR-FT-IR Spectral Collection of Conservation Materials in the Extended Region of 4000-80 Cm ${ }^{-1}$. Anal. Bioanal. Chem. 2016, 408, 3373-3379. [CrossRef]

37. bt Ruslin, F.; Yamin, B.M. Oxidation of Ferrocene by Thiocyanic Acid in the Presence of Ammonium Oxalate; AIP Publishing LLC: Melville, NY, USA, 2014. [CrossRef]

38. Sengupta, A.K.; Nandi, A.K. Complex Carbonates of Iron(III). Z. Anorg. Allg. Chem. 1974, 403, 327-336. [CrossRef]

39. Barreto, W.J.; Barreto, S.R.G.; Moreira, I.; Kawano, Y. Iron Oxide and Pyrocatechol: A Spectroscopy Study of the Reaction Products. Quim. Nova 2006, 29, 1255-1258. [CrossRef]

40. Devaman, R.H.P.; Alagar, M. Synthesis and Characterisation of Iron II Hydroxide Nano Particles. Elixir Nanotechnol. 2013, 61, 16845-16848.

41. Olvera Venegas, P.N.; Hernández Cruz, L.E.; Lapidus, G.T. Dissolution of Iron from Oxides in a Solution of Citric Acid and Sodium Thiosulfate. Adv. Mater. Res. 2014, 976, 114-118. [CrossRef]

42. Freitas, S.K.S.; Oliveira, F.L.; Dos Santos, T.C.; Hisse, D.; Merlini, C.; Machado, C.; Esteves, P.M. A Carbocationic Triarylmethanebased Porous Covalent Organic Network. Chem. Eur. J. 2020, 27, 2342-2347. [CrossRef]

43. Freitas, S.K.S.; Oliveira, F.L.; Merlini, C.; Justo, E.P.; Gioda, A.; Esteves, P.M. Dye-based Covalent Organic Networks (CONs). J. Phys. Mater. 2020, 3, 025011.

44. Amamoto, Y.; Kikuchi, M.; Masunaga, H.; Sasaki, S.; Otsuka, H.; Takahara, A. Reorganizable Chemical Polymer Gels Based on Dynamic Covalent Exchange and Controlled Monomer Insertion. Macromolecules 2009, 42, 8733-8738. [CrossRef]

45. González-Pelayo, S.; López, E.; Borge, J.; de-los-Santos-Álvarez, N.; López, L.A. Ferrocene-Decorated Phenol Derivatives by Trapping ortho-Quinone Methide Intermediates with Ferrocene. Eur. J. Org. Chem. 2018, 2018, 2858-2862. [CrossRef]

46. Cruz, H.; Gallardo, I.; Guirado, G. Understanding specific effects on the standard potential shifts of electrogenerated species in 1-butyl-3-methylimidazolium ionic liquids. Electrochim. Acta 2008, 53, 5968-5976. [CrossRef]

47. Deblase, C.R.; Silberstein, K.E.; Truong, T.T.; Abruña, H.D.; Dichtel, W.R. B-Ketoenamine-Linked Covalent Organic Frameworks Capable of Pseudocapacitive Energy Storage. J. Am. Chem. Soc. 2013, 135, 16821-16824. [CrossRef] [PubMed]

48. Scholz, F. Electroanalytical Methods: Guide to Experiments and Applications; Springer: Berlin/Heidelberg, Germany, 2010. [CrossRef]

49. Khan, F.S.T.; Waldbusser, A.L.; Carrasco, M.C.; Pourhadi, H.; Hematian, S. Synthetic, spectroscopic, structural, and electrochemical investigations of ferricenium derivatives with weakly coordinating anions: Ion pairing, substituent, and solvent effects. Dalton Trans. 2021, 50, 7433-7455. [CrossRef]

50. Wu, M.-S.; Tzu-Ling, L.; Wang, Y.-Y.; Wan, C.-C. Assessment of the wettability of porous electrodes for lithium-ion batteries. J. Appl. Electrochem. 2004, 34, 797-805. [CrossRef] 